\title{
Remote supervision of autonomous agricultural sprayers: The farmer's perspective
}

\author{
Uduak Edet, Eric Hawley and Danny D. Mann \\ Department of Biosystems Engineering, University of Manitoba, Winnipeg, MB R3T 5V6, Canada \\ Corresponding Author: Danny Mann (Danny.Mann@umanitoba.ca)
}

\begin{abstract}
The autonomous agricultural machine may soon be a reality. For it to be commercially viable, designers must also consider the design of the interface that will be used to remotely supervise the operation of the autonomous machine. Before the interface can be designed, however, it is necessary to understand the information required by the individual supervising the machine from a remote location Hence, the goal of this study was to determine the expectations of farmers regarding autonomous agricultural machines (specifically, an autonomous sprayer), and to determine the essential information that should be provided on the interface to enable the farmer to supervise the operation of an autonomous sprayer remotely. A questionnaire was developed and distributed to farmers and agriculture students attending western Canadian universities. In a follow-up study, experienced, operators were then asked to rank each parameter that was recommended from the survey using a five-point Likert scale. Findings indicated that sprayer operators are willing to accept an autonomous sprayer. However, to increase the ease of adoption, certain conditions need to be met. Parameters and features that were recommended varied in their level of importance and frequency of usage. These results will help designers minimize the chance of overcrowding the interface with irrelevant information. It will also assist designers with organization of information based on the needs of the farmer and in a way that will increase the situation awareness of the farmer.
\end{abstract}

\section{KEYWORDS}

Agricultural machine, autonomous, remote supervision, sprayer, interface design.

\section{RÉSUMÉ}

Les machines agricoles autonomes seront bientôt une réalité. Afin d'en assurer la viabilité commerciale, les concepteurs doivent aussi considérer le design de l'interface qui sera utilisée pour surveiller à distance le fonctionnement des machines autonomes. Pour ce faire, il est nécessaire de comprendre quelles sont les informations nécessaires aux personnes qui supervisent ces machines à distance. Par conséquent, le but de cette étude était de déterminer les attentes des agriculteurs relativement aux machines autonomes (particulièrement un pulvérisateur autonome) ainsi que les renseignements essentiels que devrait fournir l'interface pour permettre à l'opérateur de superviser à distance le fonctionnement du pulvérisateur autonome. Un questionnaire a été élaboré et distribué aux agriculteurs et aux étudiants des programmes agricoles des universités de l'Ouest canadien. Dans une étude subséquente, des opérateurs d'expérience ont eu à évaluer chaque paramètre qui avait été recommandé par un sondage en utilisant une échelle Likert en cinq points. Les conclusions montrent que les opérateurs de pulvérisateur sont prêts à adopter un pulvérisateur autonome. Toutefois pour en faciliter l'adoption, certaines conditions doivent être satisfaites. Les paramètres et les fonctionnalités qui ont été recommandés présentent des différences au niveau de l'importance et de la fréquence d'utilisation. Ces résultats aideront les concepteurs à minimiser les risques de surcharge de l'interface avec des renseignements inutiles. Ils seront aussi utiles aux concepteurs pour organiser l'information selon les besoins des opérateurs et de façon à augmenter pour l'agriculteur la connaissance de la situation au champ.

\section{MOTS CLÉS}

machine agricole, autonome, supervision à distance, pulvérisateur, conception d'interface.

\section{CITATION}

Edet, U., E. Hawley and D.D. Mann. 2018. Remote supervision of autonomous agricultural sprayers: the farmer's perspective. Canadian Biosystems Engineering/Le génie des biosystèmes au Canada 60: 2.19-2.31

https://doi.org/10.7451/CBE.2018.60.2.19 


\section{INTRODUCTION}

Remote supervision of an automated system is not a novel idea. Remote supervision has been practiced for several decades, but is most evident in space, marine, aviation, military, nuclear, and industrial processes (Madni et al. 1983; Dorais et al. 2003; Reising 2003; Schreckenghost et. al. 2008). For example, unmanned ground and aerial vehicles have been deployed to the battlefield by the military. In some cases, an operator is expected to supervise multiple vehicles from a base station. This role is aided and performed through an interface that has visual information of the environment to enable understanding of the situation before engagement (Lewis, 2013). Robots have been sent to the moon's surface during space exploration. Since the location is not habitable for humans, monitoring of the robot is often done from a distant location via an interface. Similarly, in marine operations, remote supervision has been used to monitor and control the activities of underwater manipulation robots (Madni et al. 1983).

In the agricultural sector, remote supervision has been practiced in grain storage facilities, livestock buildings, irrigated fields, and for crop scouting using drones. For example, the One-Step Automation seed processing control system (One-Step Automation, Niverville, MB) has an application that provides live camera feeds and real time bin status that can be received remotely via phone for the farmer to take necessary action (e.g., control equipment speed). Unmanned aerial vehicles (or drones) have been used to remotely acquire crop, soil, and environmental data (Zhang and Kovacs 2012). The introduction of machine-machine interaction (or machine synchronization) in tractors has enabled operators to remotely access information from the other tractors while they are in operation (Deeken et al. 2018; John Deere 2018)

Currently, researchers and manufacturers are working to achieve full automation of agricultural field machines meaning that tractors, sprayers, and combines, soon, may not require an operator to be physically present to complete field operations. However, considering the uncertain conditions within which these machines function and that it is difficult to automate the higher-level reasoning required to develop tasks, allocate resources, monitor the execution of tasks, and intervene in cases of emergencies that go beyond the machine's capability (Alexander et. al. 2009; Schreckenghost et. al. 2008), it is important that the human remain in the control loop.

For the human to remotely interact with an automated machine to perform these tasks, an interface is required (Stentz et al. 2002; Blackmore et al. 2007). Great importance must be placed on the design of the interface so that the information presented to the farmer does not exceed their ability to process and use the information (Rakhra et al. 2013). Endsley et al. (2003) has suggested that adopting a user-centered approach will help designers to include only information that is needed by the farmer thereby reducing the chance of overcrowding the interface with irrelevant information. They also presented a systematic approach for achieving a user-centered interface that consists of i) information gathering using requirement analysis,

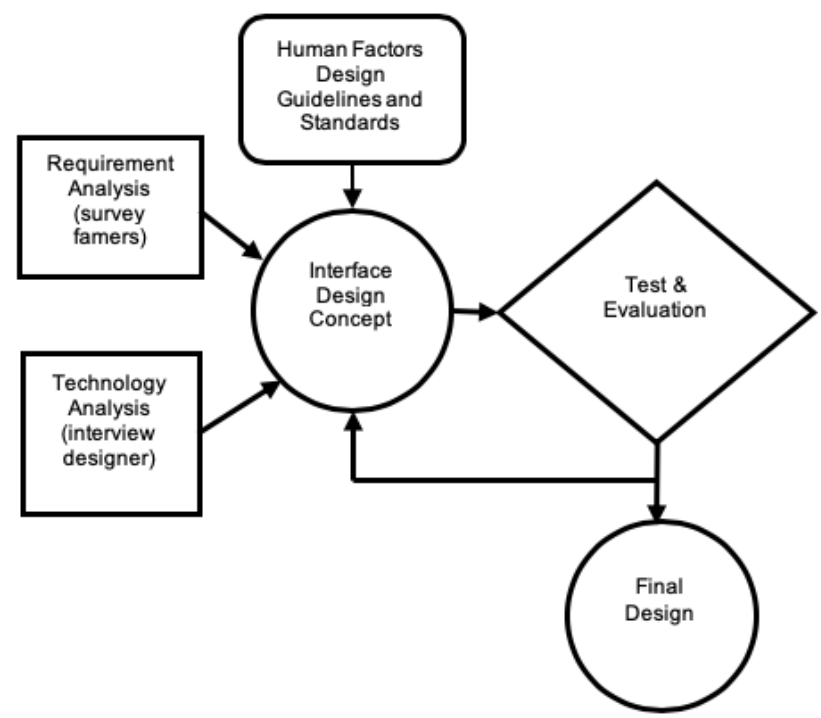

Fig. 1. Human interface design process (adapted from Endsley et al. 2003).

technology analysis, and design standards ii) conceptual design, iii) testing and evaluation, and iv) final design (Fig. $1)$.

Requirements analysis involves identifying tasks (what it is and why it is needed) as well as the role of the potential user. Environmental conditions, user characteristics (age, gender, experience, and computer/IT experience) and operational requirements that could affect the design can be obtained during this phase (Endsley et al. 2003). Technological analysis, on the other hand, means evaluating the various tools and technology available to determine the most suitable for the intended user (Endsley et al. 2003). It is usually carried out alongside the requirement analysis.

The actual interface design and prototype development are performed during the design concept phase. Designers take into consideration the various design principles (Christopher et al. 2004; Mark et al. 2008; Rakhra et al. 2014) and standards (Deborah et al. 2005) to achieve a usercentered interface. The interface testing and evaluation phase involve assessing how well the design/prototype meets the set criteria. It also provides a means for obtaining feedback from potential users on how to improve the design. This process is iterative until the design requirements are met.

After the design requirements have been met and stakeholders are satisfied with the outcome of the design and evaluation, the final design can then be presented to the client/public.

In this paper, our focus is on the requirements analysis phase of the design process. i.e. to gather information about the users, their tasks, and environmental conditions that will affect the design. Task analysis is a common tool for identifying task goals and understanding human-machine interaction. It uses tools such as survey, interview, and observation of potential users. Meusel et al. (2015) noted that the tasks performed by current agricultural machine 


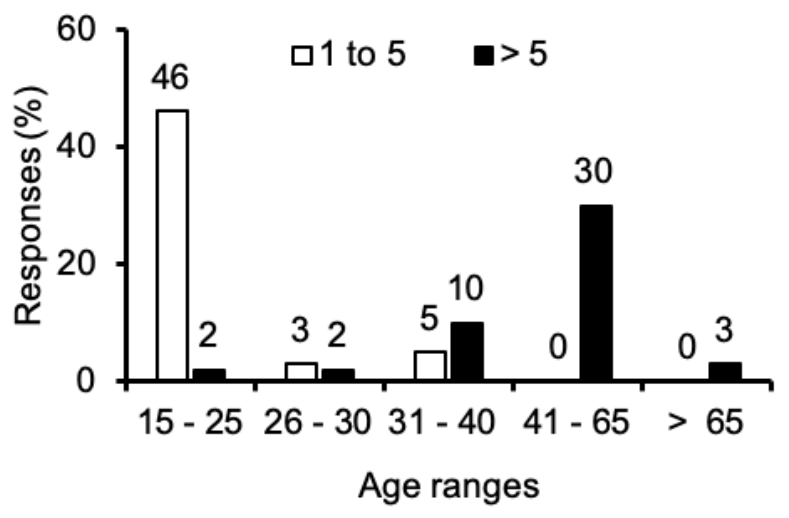

Fig. 2. Ages of respondents in relation to their years of experience in spraying $(n=61)$.

operators can be categorized in three areas: i) the immediate work in front of them, ii) coordinating upcoming events, and iii) high level organizational responsibilities. They went further to develop an operator centered task analysis (OCTA) methodology to identify and understand the processes involved in planting. Young (2003) performed a task analysis for operation of an agricultural sprayer. The tasks identified included chemical application (i.e., setting the correct rate of application, turning the application system on and off, checking boom height and flow, periodic checking for plugged nozzles, refilling the sprayer), navigation (i.e., planning and completing parallel passes across the field, spraying around obstacles), and controlling functions (i.e., adjusting travel speed, steering the sprayer along the parallel path, boom height control).

Numerous advances are being made to automate the tasks associated with operating an agricultural sprayer. Unfortunately, little work has been done to highlight the information that should be provided to farmers to enable them to supervise the operations of autonomous agricultural machines remotely. Hence, the objectives of this study were to determine: (i) the expectations of farmers regarding autonomous sprayers, and (ii) the essential information that should be provided on the interface to enable the human to supervise the operation of an autonomous sprayer remotely. The study focused on the agricultural sprayer given the prominent role that it plays in crop production.

\section{MATERIALS AND METHODS}

The study was carried out in two phases. In Phase 1, questions were developed based on information gathered through completion of a literature search on the topic of remote supervision, review of operator manuals for agricultural field machines, and a visit to an agricultural machinery exhibition featuring emerging technology that has not yet been described in the literature. Different question types were used to maximize the quality of the data (i.e., in some instances it was deemed best to present a list of options for selection while in other instances questions were open-ended, so comments were encouraged). The questionnaire comprised of two sections. The first section gathered demographic information on respondents (such as age, gender, place of residence, etc.) while the second

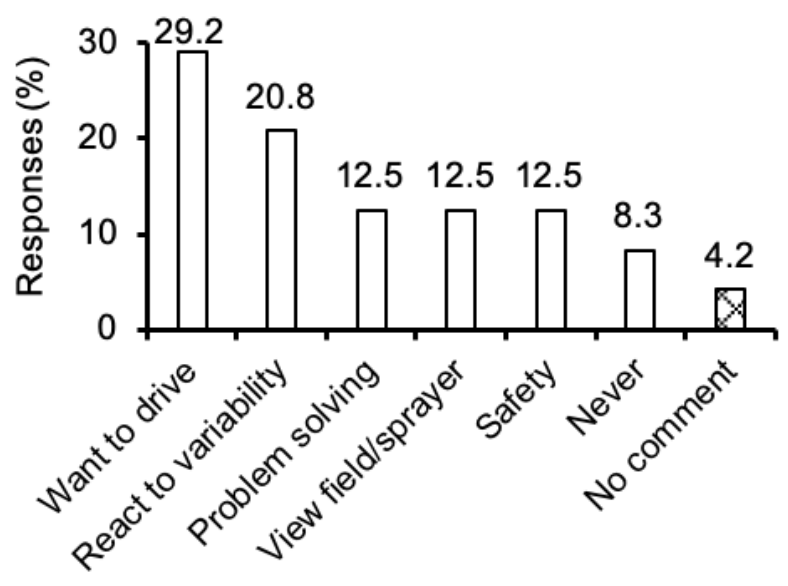

Fig. 3. Concerns of respondents who rejected autonomous sprayer (open ended comments were grouped using the categories on the $x$ axis. $n=19$ ).

section focused on the expectations of farmers with respect to autonomous sprayers, how these sprayers would be remotely supervised, and what information would be required to effectively supervise the sprayer. A condensed version of the Phase 1 questionnaire is included in Appendix A. The questionnaire was distributed to farmers and agriculture students attending universities in the three Canadian prairie provinces (i.e., Alberta, Saskatchewan, and Manitoba). Four universities and nine distinct producer groups were contacted to assist with distribution of the questionnaire.

Phase 2 of the study was used to gather more detailed information on the parameters of sprayer functions identified by at least $50 \%$ of respondents on the Phase 1 questionnaire. A total of 38 experienced sprayer operators were contacted with the help of various producer groups and industrial contacts within the three prairie provinces to ensure each province was represented. Participants were asked to rank how frequently or rarely they used or needed each parameter that was recommended by respondents during the first phase of the study. A five-point Likert scale (always, very frequently, occasionally, rarely, never) was adopted to organize their responses. A condensed version of the Phase 2 questionnaire is included in Appendix B. Prior to each phase of the study, ethics approval was obtained from the research ethics board of the University of Manitoba, Winnipeg, Manitoba. In both cases, participants could either respond online using Survey Monkey or fill a hardcopy of the questionnaire.

\section{RESULTS AND DISCUSSIONS}

\section{Phase 1: Respondent's demographics}

A total of 141 responses (116 online and 25 hardcopies) were collected during the first phase of the study (November 2016 to January 2017), but 80 were excluded either because the questionnaire was incomplete, or the respondent had no experience with use of an agricultural sprayer. Of the 61 eligible responses, $3 \%$ were female and 


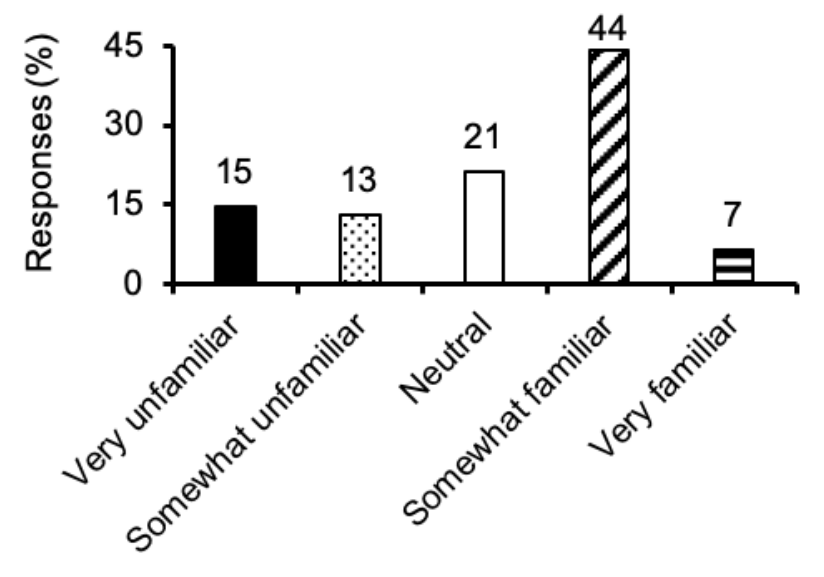

Fig. 4. Respondents level of familiarity with remote supervision $(n=61)$.

$97 \%$ were male. Manitoba had the highest number of respondents $(71 \%)$ followed by Saskatchewan $(26 \%)$ and Alberta (3\%). Overall, $61 \%$ of respondents resided in rural regions across the three provinces.

Respondents were mainly farm owners within the age categories of 15-25 years and 41-65 years (Fig. 2). Just over half of respondents (54\%) had 1-5 years of experience in spraying while the remaining respondents $(46 \%)$ had more than 5 years of experience (Fig. 2). Most of the lessexperienced sprayer operators were younger than the moreexperienced operators indicating that farmers do not start operating sprayers at an older age but begin when they are younger and develop their skill and knowledge of the machine as they age.

\section{Expectations with respect to autonomous sprayers and remote supervision}

Autonomous sprayers Respondents were asked if they would accept an autonomous sprayer; 31\% said "No" and $69 \%$ indicated "Yes". Respondents who indicated "No" were then asked to describe the changes that should be made before they would accept an autonomous sprayer. Their comments have been grouped into seven categories for easy presentation (Fig. 3). Eight percent (8\%) stated that they would "never" adopt an autonomous sprayer, 29\% wanted to continuously drive the sprayer, and $4 \%$ did not comment (Fig. 3). The remaining $58 \%$ of respondents had other concerns: like safety, reacting to variability in field/soil conditions, monitoring spray patterns, managing drift, viewing the crop while spraying, nozzle plugging, machine breakdown, avoiding obstacles, complexity of setting up, controlling and repairing the sprayer, and the actual cost of the sprayer. If all these concerns can be addressed by manufacturers, it could further increase the percentage of farmers and custom applicators within the Canadian prairie provinces who would be willing to accept autonomous sprayers from $69 \%$ to $87 \%$.

Remote supervision Regarding farmers' views of remote supervision, $75 \%$ of respondents liked the idea of remote supervision while $44 \%$ and $7 \%$ were "somewhat familiar" and "very familiar", respectively, with the concept of

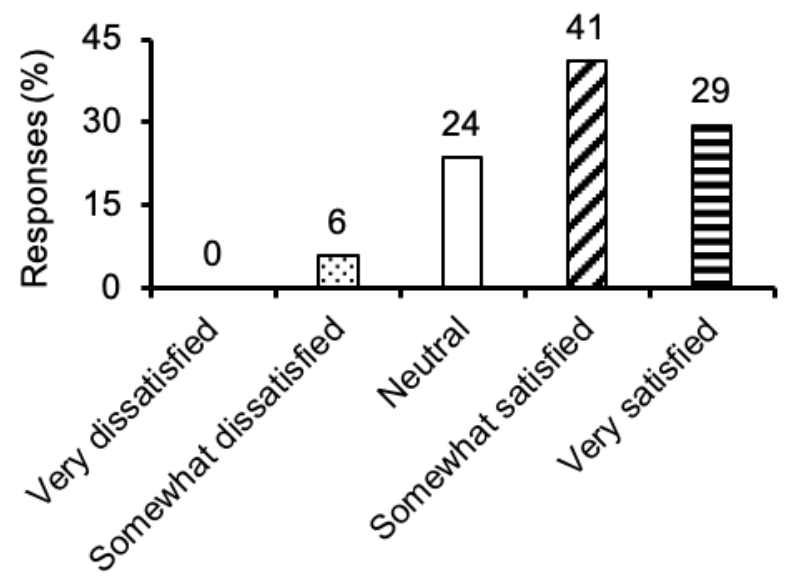

Fig. 5. Respondents level of satisfaction towards remote supervision of another farm operation $(n=17)$.

remote supervision (Fig. 4). However, only $28 \%$ of the survey respondents had monitored other types of farm activity remotely of which $70 \%$ were "satisfied" with the outcome (Fig. 5). Unfortunately, respondents were not asked to specify which activity they had remotely supervised. However, from the literature (Vellidis et al. 2015) and a recent visit to a farm show featuring emerging technology in agricultural machinery that has not been described in the literature, remote supervision is being used to monitor and control certain processes in grain storage facilities, livestock buildings, irrigation systems, crop scouting, machine-machine synchronization, and machine activities.

Figure 5 also revealed that no respondent was "very dissatisfied" monitoring other farm activities remotely. The results show that a large proportion of respondents are at least somewhat familiar with the concept of remote supervision, and the preliminary experiences have been positive based on the level of satisfaction reported.

Respondents were also asked to indicate how comfortable or uncomfortable they would be supervising an autonomous sprayer remotely. Overall, respondents were "somewhat comfortable" but of those who were willing to accept an autonomous sprayer, the majority of them were somewhat comfortable (Fig. 6). As discovered in the previous section, farmers have concerns about the reliability of future autonomous sprayers. They are aware of the liability issues that may arise if anything goes wrong and cannot be managed on time. Hence, they are "somewhat comfortable". However, their comfort with autonomous sprayers and remote supervision might increase as the level of trust in autonomous sprayers increases (as experience with previous innovations such as autosteer have demonstrated).

Regarding the location of the automation interface, $41 \%$ of respondents wanted it "close to the field" while $38 \%$ and $21 \%$ preferred having it "anywhere" and "in the farm office", respectively. No respondent $(0 \%)$ wanted the remote station to be located "outside the farm". Upon further analysis, it was discovered that respondents with 


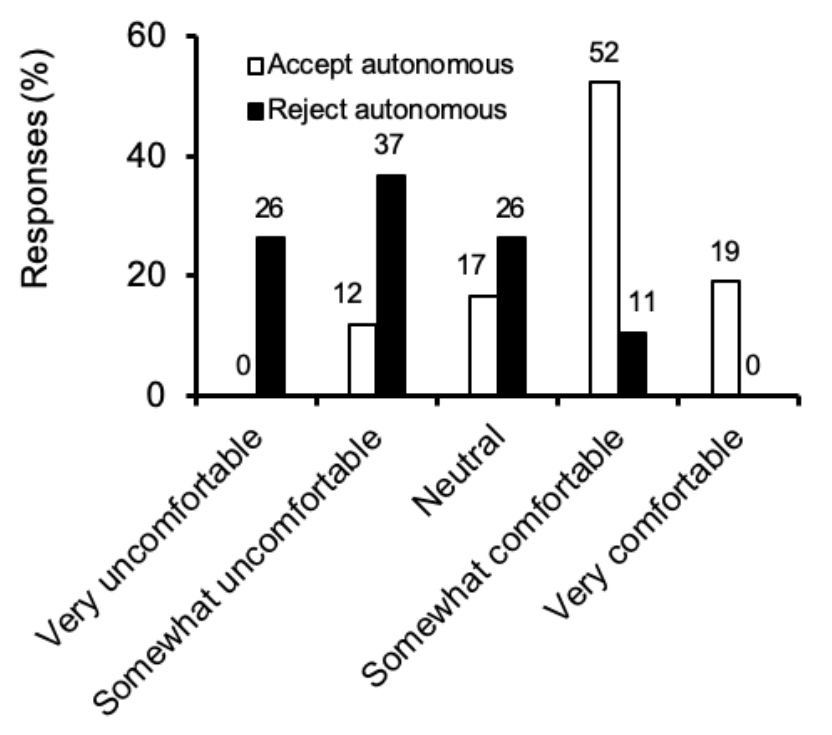

Fig. 6. Comfort level of respondents regarding the remote supervision of an autonomous sprayer (n: accept autonomous sprayer- 42, reject autonomous sprayer-19).

previous experience of remote supervision (of other farm activities) were comfortable having the remote station anywhere while respondents without any related experience wanted the station to be located close to the field (Fig 7). The difference in choice of location reflects the level of trust and experience in relation to remote supervision. Farmers with experience in remote supervision have a higher level of trust in the system and can be "anywhere" while farmers without experience appear to be reluctant to distance themselves from the sprayer. Hence, they prefer to be "close to the field" (Fig. 7). Regardless of experience, no respondents wanted to be "outside the farm" (Fig. 7).

\section{Interface characteristics}

To determine what medium will be used as the interface, respondents were asked to indicate what type of device they would use when interacting with an autonomous sprayer. A majority of respondents $(93 \%)$ indicated that the device should be portable while $5 \%$ preferred it to be stationary. The remaining $2 \%$ of respondents wanted both options. The result depicts how farmers work. They prefer to multi-task, moving from one place to another to attend to various tasks around their farm. Hence, they would not want to be confined to one location for hours doing only one task. The results also suggest that farmers will not want to monitor the sprayer continuously. Further analysis revealed that the device for interaction should be a tablet (27\%), phone (24\%), desktop/laptop (18\%), or a combination of two or more of these devices. However, $8 \%$ of respondents felt that there was no need for interaction. They felt that an autonomous sprayer should be able to perform the set tasks effectively without human supervision.

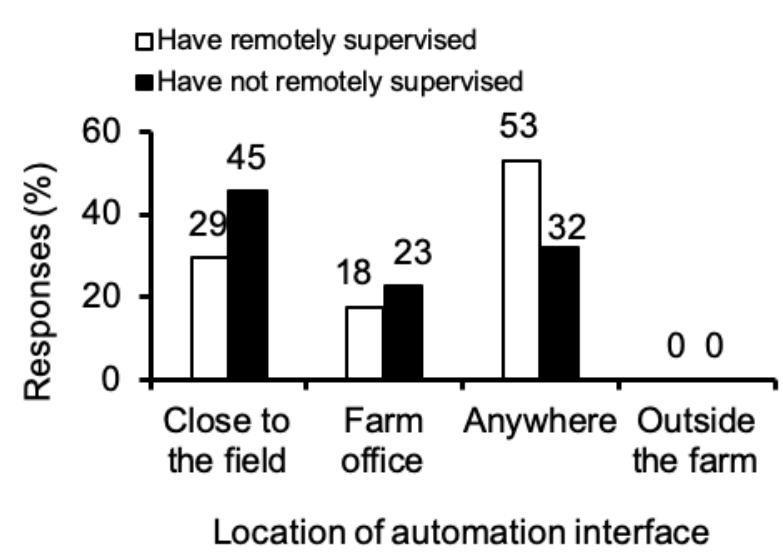

Fig. 7. Location of the automation interface based on experience of respondents ( $n$ : have remotely supervised- 17 , have not remotely supervised44).

Overall, respondents would prefer to communicate with an autonomous sprayer using button/tab (Fig. 8). Hence, the finding supports either the use of a phone and tablet as the medium for interacting with the sprayer. Aside from button/tab, the next preferred mode was "text", followed by "audio" (Fig. 8). Having multiple options for communication may also be valuable. However, the primary mode of communication should be tab/button. Hence, it can be inferred that farmers/custom applicators would prefer using either phone or tablet as the medium for interacting with autonomous sprayers.

Respondents were also asked to indicate their preferred mode for commencing operation (i.e., starting the autonomous sprayer). Forty-eight percent (48\%) of respondents chose to manually start the sprayer on site, $46 \%$ preferred to use tab or button from a remote location, and $3 \%$ wanted to use text command from a remote location.

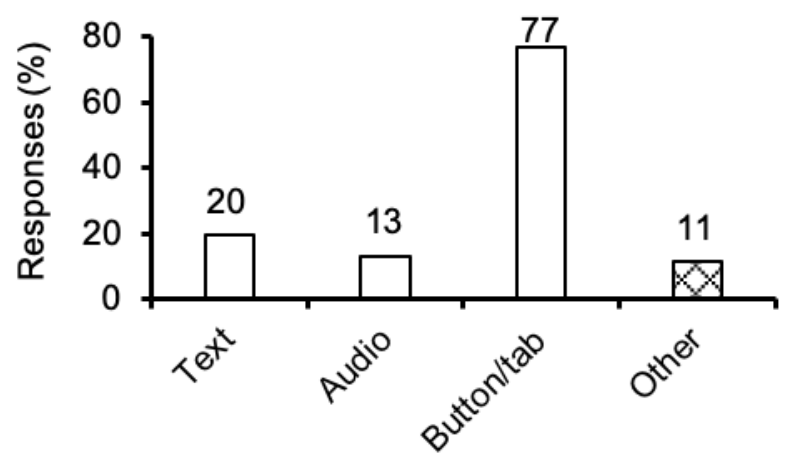

Communication modes

Fig. 8. Respondents' opinions on the medium for interacting with an autonomous sprayer. (multiple responses were allowed; $n=61$; Audio: use of voice command, Text: typing instruction, Button/tab: touching a short projecting device, like car radio button and touchscreen, to transmit instruction). 


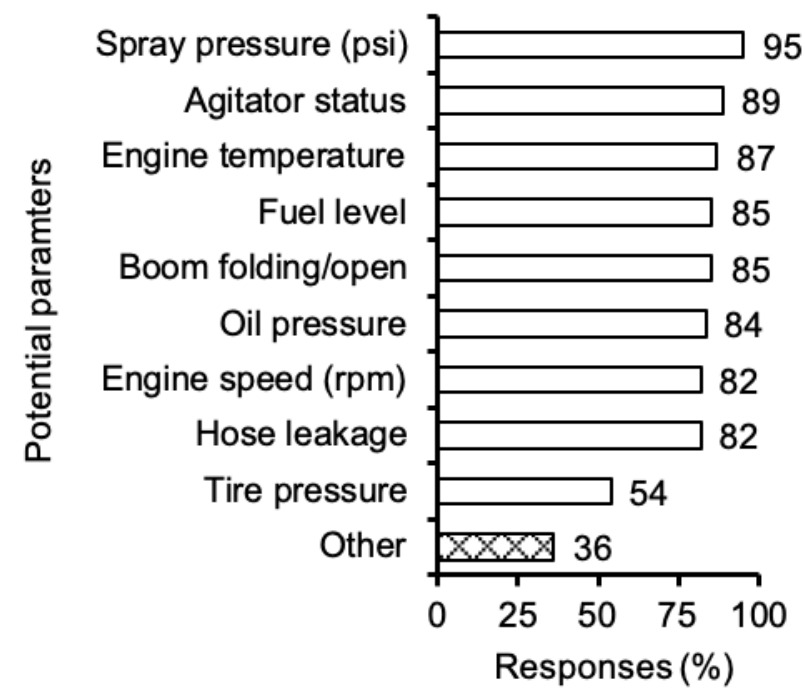

Fig. 9. Parameters for machine status as determined by respondents $n=61$; respondents were instructed to choose all that applied from a given list as well as provide their own suggestions based on Likert scale adopted by the authors, >75: very important, $51-75 \%$ : important, $25-50 \%$ : less important, and < 25: not important).

The remaining 3\% would like multiple options. The result was also found to be independent of respondents' experience towards remote supervision.

Current operators of agricultural sprayers complete tasks like filling the tank and diagnosing minor problems before commencing operation. Hence, respondents who preferred to start the sprayer manually might want to turn on the sprayer while performing these other tasks. On the other hand, respondents who favoured the use of technology to remotely start the sprayer might view it as giving them the ability to either start the autonomous sprayer from any location within the farm or restart the sprayer in cases of emergencies whereby the sprayer shuts itself off and needs assistance to resume operation. Hence, having both methods for commencing operation would be valuable, since it would accommodate both groups of respondents, thereby increasing the percentage of farmers who will be willing to accept an autonomous sprayer.

\section{Interface elements and functions}

Respondents were asked to specify which parameters should be included in the interface from a given list of parameters. They were also encouraged to include their own suggestions. We divided the parameters into five groups to simplify their responses: 1) machine status; 2) spraying functions; 3) navigation features; 4) visual needs; and 5) warnings and notifications. A five-point ranking scale (>75\%: very important, $51-75 \%$ : important, $25-50 \%$ : less important, and $<25$ : not important) was used to group parameters based on the number of respondents who recommended such parameters.

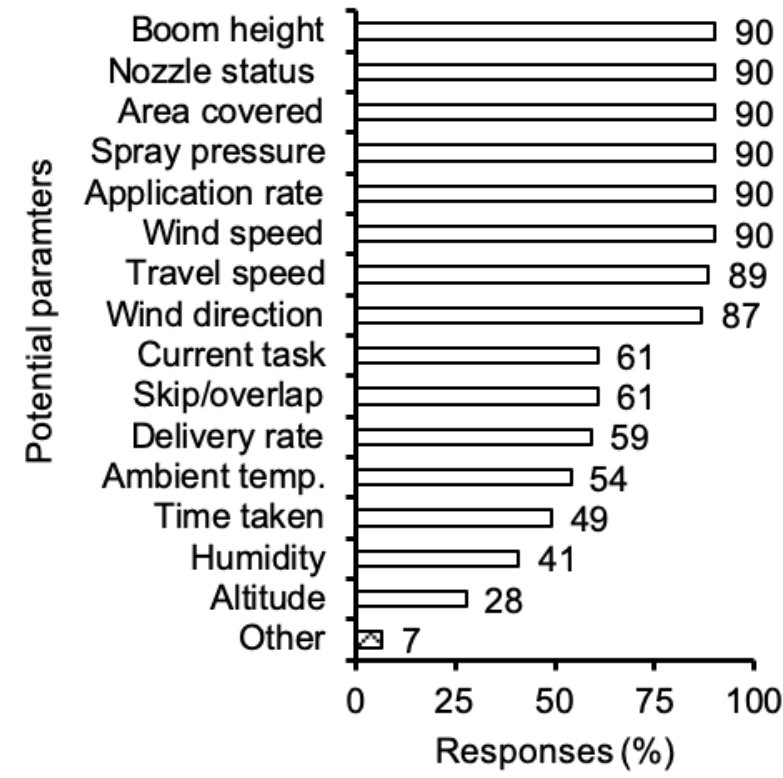

Fig. 10. Parameters for spraying functions as determined by respondents; $n=61$; Respondents were instructed to choose all that applied from a given list as well as provide their own suggestions based on Likert scale adopted by the authors, >75: very important, $51-75 \%$ : important, $25-$ $50 \%$ : less important, and < 25: not important).

Machine status These are parameters that are related to the functioning of the autonomous sprayer (i.e., non-spraying operations). Figure 9 presents respondents' opinions regarding which parameters will be needed to understand the status of the sprayer. The results revealed that respondents needed all the parameters that were presented under "machine status". However, the number of responses vary from parameter to parameter (Fig 9). Based on the authors' ranking scale that was adopted, all but tire pressure were considered "very important" as more than $75 \%$ of respondents recommended them. Most respondents considered tire pressure as "important". Other parameters that were suggested, but not included in the machine status list were slippage, GPS status, and autosteer status.

Spraying functions Respondents' opinions regarding parameters that would be needed to remotely understand the actual spraying operation are shown in Fig. 10. Most respondents $(>75 \%)$ selected boom height, nozzle status, area covered, spray pressure, application rate, travel speed, wind speed, and direction. Therefore, based on the ranking scale, they would be considered "very important". Similarly, ambient temperature, skip/double application, delivery rate, and current task would be considered "important" while the "least important" parameters were humidity, time taken, and altitude (Fig. 10). Some respondents suggested field condition, tank level, chemical mix in the tank, sectional control status, gallons per hour sprayed, number of fills, and droplet size as parameters that will be needed to remotely understand the actual spraying operation. 


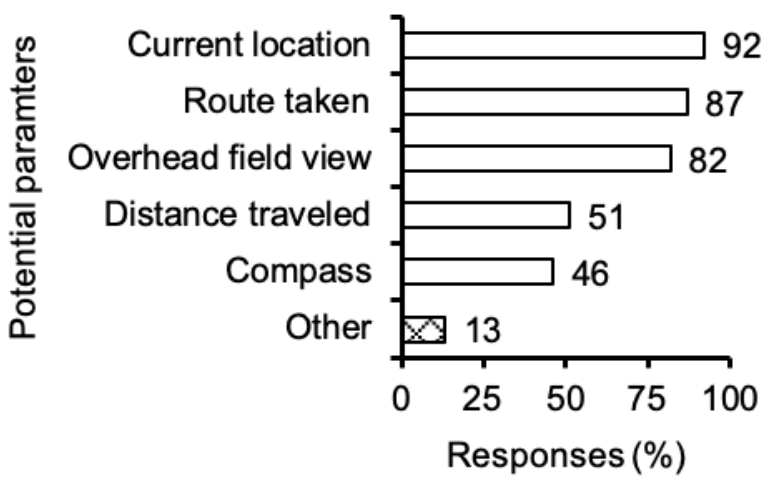

Fig. 11. Parameters for navigation features as determined by respondents; $n=61$ respondents were instructed to choose all that applied from a given list as well as provide their own suggestions based on Likert scale adopted by the authors, $>75$ : very important, $51-75 \%$ : important, $25-$ $50 \%$ : less important, and < 25: not important).

Navigation features At least, $75 \%$ of respondents indicated that they would need information on route taken, current location, and overhead view to understand and monitor the movement (navigation) of an autonomous sprayer. Therefore, these parameters would be "very important" (Fig. 11). Other parameters that were suggested, but not included in the navigation features' list were "planned route", and "coverage map".

Visual needs Respondents were asked if they would require live video of the autonomous sprayer and its environment during operation. Eighty-five percent $(85 \%)$ of respondents said "Yes" while 15\% indicated "No". Of the respondents that said "Yes", 84\% indicated the field ahead (front view), $74 \%$ selected both right and left boom of the sprayer, and
$69 \%$ requested the rear view (Fig. 12a). When asked to specify their most preferred view, most respondents picked the field ahead (front view), followed by the rear view (Fig. $12 \mathrm{~b})$. Other views that were suggested included the entire boom/nozzles, overhead view, and high up near the back of the sprayer looking ahead. Some respondents (4\%) felt that providing just one view will not be enough to properly understand what is going on in the field. They suggested having either all four views or both ahead (front) and entire boom view. This is understandable since during field operation, current sprayer operators look ahead to either know when to turn or avoid obstacles as well as look at the boom to check the spray pattern, plugged nozzle, drift, boom height, and side obstacles. However, for an autonomous sprayer, all/some of these factors might be handled by the sprayer or presented as indicators on the interface. Hence, some of these views might not be required to understand what is going on in the field. The results from Fig. 12b suggests that farmers can do away with some of these views.

Warnings and notifications Figure 13 presents respondents' opinions regarding which conditions and functions required notifications or warnings. Aside from route change and skip/double application, at least $75 \%$ of respondents indicated that they wanted to receive updates if any abnormalities occurred in the other listed elements and conditions (Fig. 13). Hence, these parameters would be "very important" when supervising the operation of an autonomous sprayer (based on the ranking scale).

One would have thought that skip/double application would be of greater concern to the farmers, but this is not the case. Further investigation revealed that skipping and double application are negligible during spraying due to the high accuracy of GPS, autosteer and other features like individual nozzle/section control; which is why plugged

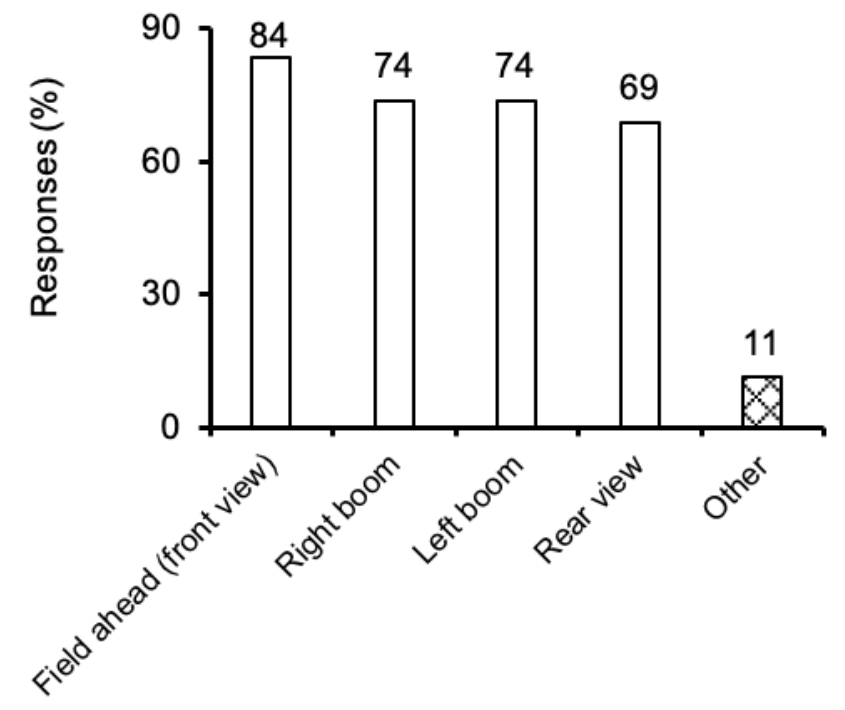

(a)

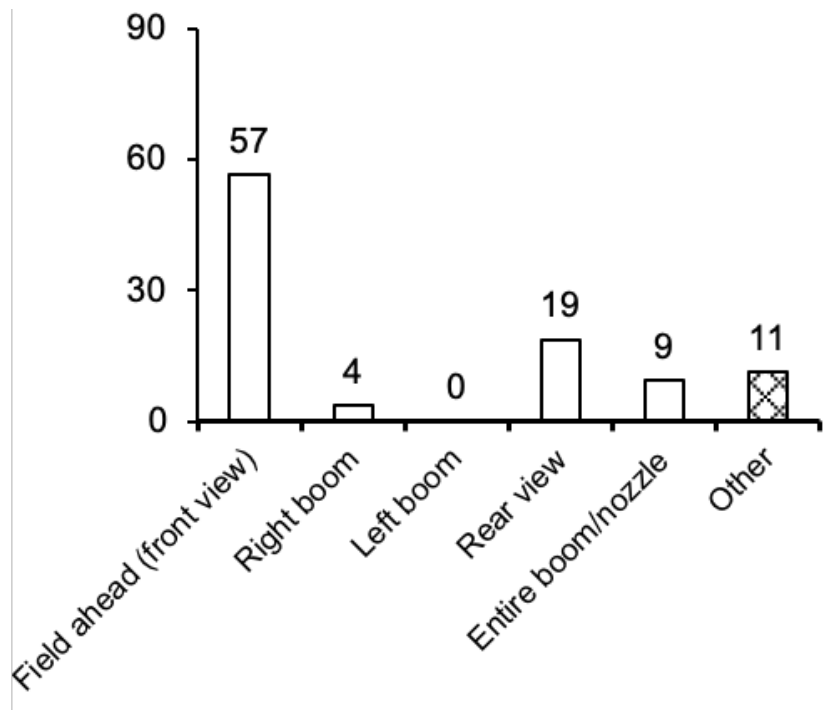

(b)

Fig. 12. Respondents opinion on (a) needed views (multiple responses were allowed) and (b) the most preferred views (single response); $\mathbf{n}=\mathbf{5 2}$. 


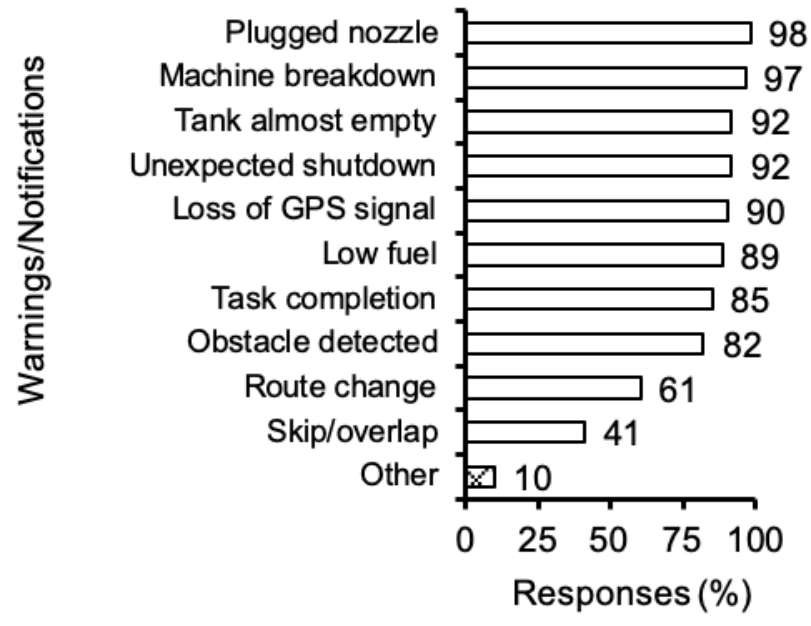

Fig. 13 Warnings and notifications as determined by respondents; $n=61$; respondents were instructed to choose all that applied from a given list as well as provide their own suggestions based on Likert scale adopted by the authors, >75: very important, $51-75 \%$ : important, 25- 50\%: less important, and < 25: not important).

nozzle, loss of GPS signal were of greater concern to farmers (Fig 14). The greatest concerns among respondents were machine breakdown, detecting obstacles, and unexpected shutdown (Fig. 14). These concerns are valid considering that any unattended irregularities among any of these conditions might either cause total shutdown of the spraying operation or liability issues.

A tabular summary of the interface requirements is shown in Table 1. The table summarizes which parameters are needed by the majority of the respondents and their level of importance with regards to supervising the operation of an autonomous sprayer. Parameters that are under the "very important" column were recommended by at least $75 \%$ of the respondents. Hence, they should be included in the interface.

\section{口Alberta \\ - Manitoba \\ -Saskachewan}

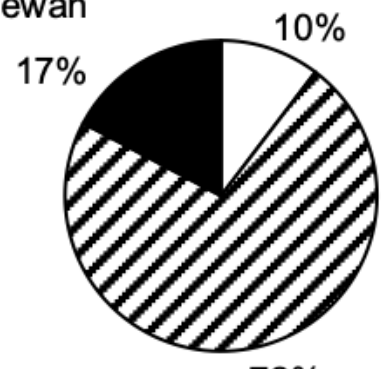

$72 \%$

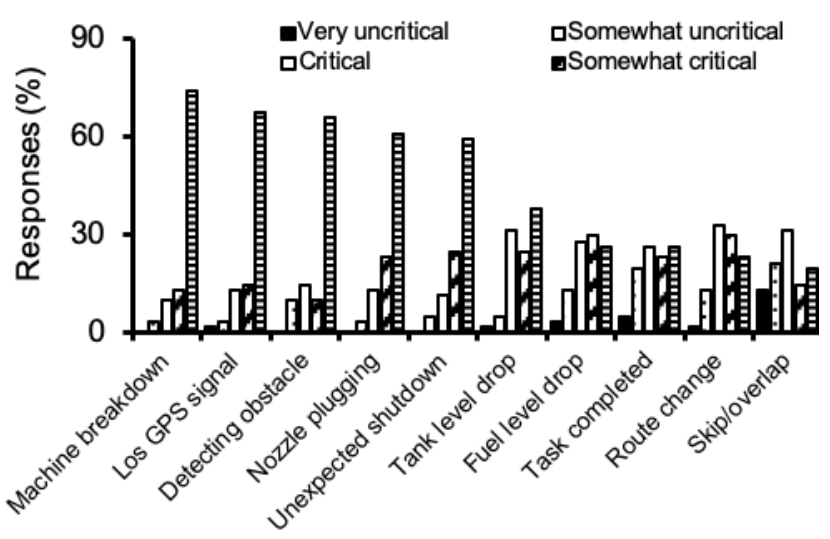

Warnings/Notifications

Fig. 14. Severity of warnings and notifications as determined by respondents $(n=61)$.

Phase 2: Operators' ranking

Of the 29 experienced operators who participated in Phase 2 of the study, only three had participated in the first phase of the study. Manitoba had the highest number of respondents followed by Saskatchewan and Alberta (Fig. $15 a)$. Twenty-eight percent $(28 \%)$ of these operators had between 2 and 5 years of experience in spraying while $52 \%$ had more than 15 years of experience (Fig. 15b).

Aside from one respondent who last operated a sprayer in 2012, the latest and earliest time a respondent had operated a sprayer was a year ago (2016), and on the day he completed the survey (October 2017), respectively (Fig. 16). Hence, respondents were very conversant with sprayers and spraying operations.

\section{Frequency of usage/viewing}

Machine status Figure 17 presents respondents' opinions regarding how frequently or rarely they needed to use machine status information. Respondents ranked hose leakage, wireless signal status (GPS) and engine speed as "always" viewed/needed, while fuel level, engine temperature, and oil pressure were identified as

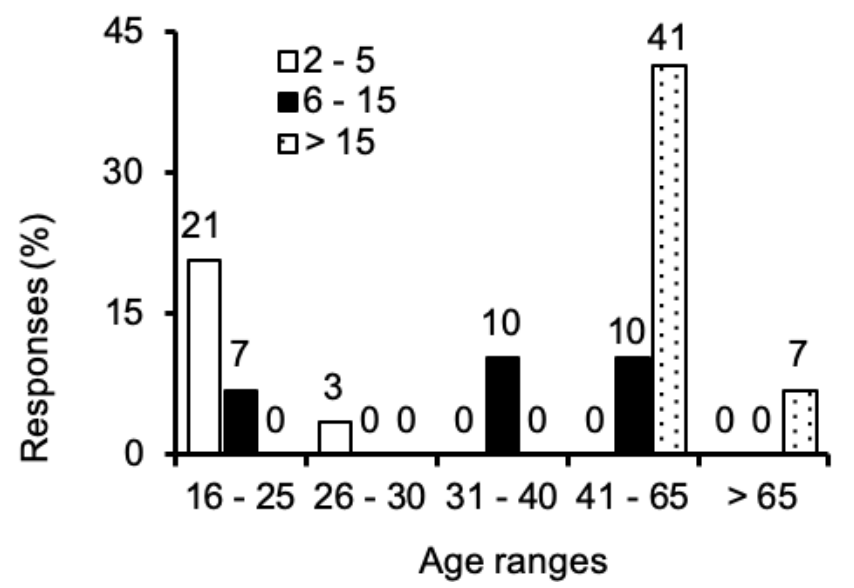

(b)

Fig. 15. Grouping of participants based on their (a) location; (b) years of experience in spraying (n=29). 
Table 1. Interface requirements as determined by the questionnaire (Phase 1).

\begin{tabular}{|c|c|c|c|c|}
\hline \multirow[b]{2}{*}{ Requirements } & \multicolumn{4}{|c|}{ Descriptions } \\
\hline & Very Important & Important & $\begin{array}{c}\text { Least } \\
\text { Important }\end{array}$ & Other suggestions/comments \\
\hline Interface Characteristics & $\begin{array}{l}\text { Portable, interact using } \\
\text { tab/buttons, }\end{array}$ & $\begin{array}{l}\text { Anywhere in } \\
\text { farm or close to } \\
\text { the field, manual } \\
\text { start or button/tab }\end{array}$ & & $\begin{array}{l}\text { Good connection, easy to } \\
\text { understand/use }\end{array}$ \\
\hline Machine status & $\begin{array}{l}\text { Engine temperature, engine } \\
\text { speed, fuel level, oil } \\
\text { pressure, hose leakage, } \\
\text { boom folding (open/close), } \\
\text { and agitator }\end{array}$ & Tire pressure & & $\begin{array}{l}\text { Autosteer status, GPS status, } \\
\text { slippage }\end{array}$ \\
\hline Spraying functions & $\begin{array}{l}\text { Boom height, nozzle status, } \\
\text { area covered, spray } \\
\text { pressure, application rate, } \\
\text { travel speed, wind speed, } \\
\text { and wind direction }\end{array}$ & $\begin{array}{l}\text { Daily } \\
\text { temperature, } \\
\text { skip/double } \\
\text { application, } \\
\text { delivery rate, } \\
\text { current task }\end{array}$ & $\begin{array}{l}\text { Humidity and } \\
\text { altitude }\end{array}$ & $\begin{array}{l}\text { Field condition, tank level, } \\
\text { chemical mix of what is in the } \\
\text { tank, sectional control, gallon per } \\
\text { hour sprayed, acres covered, area } \\
\text { sprayed per coverage, number of } \\
\text { fills, and droplet size }\end{array}$ \\
\hline Navigation features & $\begin{array}{l}\text { Route taken, current } \\
\text { location, and overhead view }\end{array}$ & Distance travel & Compass & planned route, and coverage map \\
\hline Visual & $\begin{array}{l}\text { Field ahead view (front } \\
\text { view) }\end{array}$ & $\begin{array}{l}\text { Rear view, Right } \\
\text { boom }\end{array}$ & & $\begin{array}{l}\text { Entire boom/nozzle view, overhead } \\
\text { view }\end{array}$ \\
\hline $\begin{array}{l}\text { Warning and } \\
\text { Notifications }\end{array}$ & $\begin{array}{l}\text { Plugged nozzle, machine } \\
\text { breakdown, Obstacle } \\
\text { detection, loss of GPS } \\
\text { signal, and unexpected } \\
\text { shutdown }\end{array}$ & $\begin{array}{l}\text { Tank level drop, } \\
\text { fuel level drop, } \\
\text { and route change }\end{array}$ & $\begin{array}{l}\text { Task } \\
\text { completed, and } \\
\text { skip/double } \\
\text { application }\end{array}$ & Emergency shutdown, \\
\hline
\end{tabular}

"occasionally" (Fig. 17). A majority of the respondents paid little attention to battery status, tire slippage and tire pressure (Fig. 17).

Spraying functions Regarding parameters that were related to the actual spraying functions, most respondents considered travel speed, wind speed and direction, spray pressure, application rate, nozzle status, boom height, skip/overlap and tank level as "always" viewed or needed while "time since last fill" was ranked as "rarely" needed (Fig. 18).

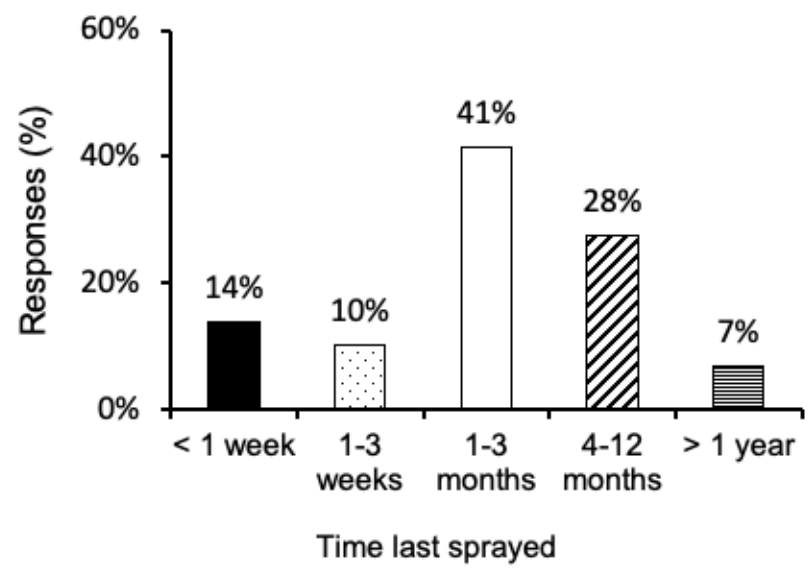

Fig. 16: Approximate time since last operation of a sprayer $(n=29)$.
Navigation features Figure 19 presents respondents' opinions regarding how frequently or rarely they utilize each navigation feature. Overall, the result showed that most respondents were "always" mindful of their "direction of travel" while other navigation features were either "occasionally" or "rarely" accessed (Fig. 19).

A tabular summary indicating the rank of each parameter is presented in Table 2. Other parameters that were suggested included engine load, object collision, and acres unsprayed. Generally, parameters and features that were ranked 'always' should be made easily accessible to the supervisor when designing the interface.

\section{CONCLUSIONS}

Farmers and custom applicators are willing to accept an autonomous sprayer. However, to increase the ease of adoption, the sprayer should be easy to operate or supervise, be able to react to variable soil and field conditions as the farmer would have done, provide information about the crop condition (crop scouting), avoid obstacles with minimal input from the farmer, not break down often, and be cost-effective.

The interface for interacting with an autonomous sprayer remotely should be a portable device that uses tabs or buttons. Based on current available devices, tablet, phone, and computers were suggested in the order presented. But, there is need to compare these devices with how the farmer works as well as the ability of each device to present information in a manner that will support the situation awareness of the user. 


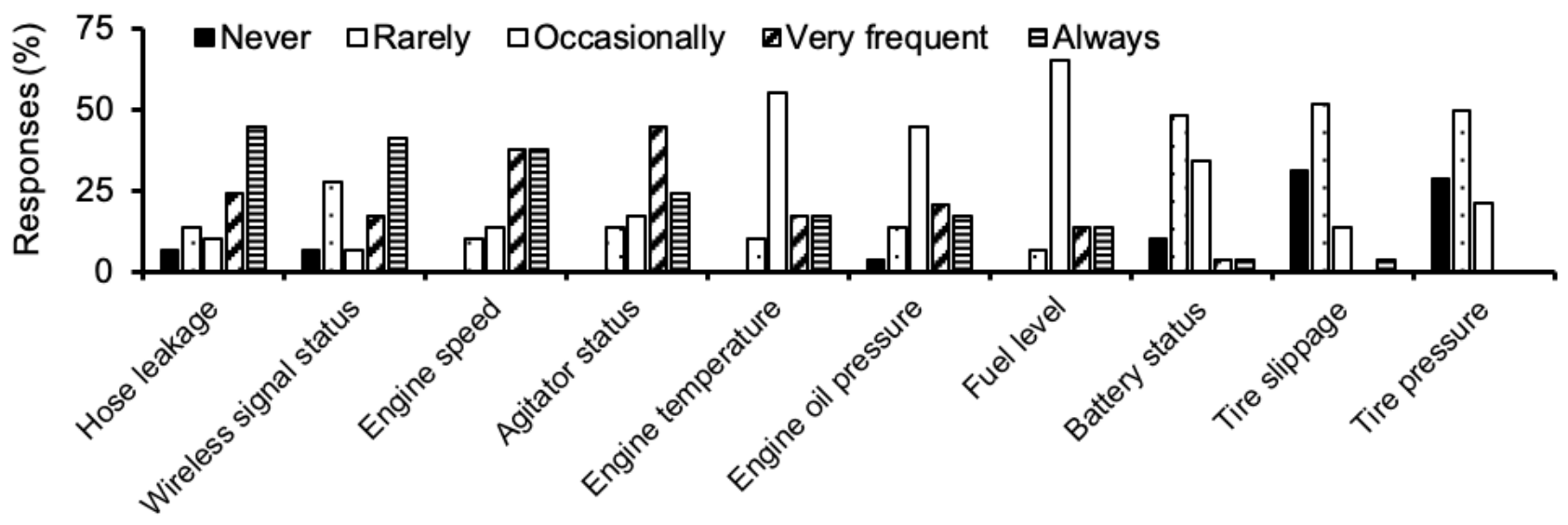

Machine status

Fig. 17. Respondents' opinions regarding how frequently or rarely they viewed or needed each machine status $(\mathrm{n}=\mathbf{2 9})$.

Recommendations were made regarding which parameters should be included in the interface. Parameters that were ranked "always" should be made easily accessible to the farmer/supervisor when monitoring the operations of an autonomous sprayer. Farmers also need live video feeds of an autonomous sprayer and its environment. These views include the view ahead (front view), rear view, left, and right boom. Other views that were suggested included the entire boom/nozzles, overhead view, and high up near the back of the sprayer looking ahead. However, further studies should be carried out to ascertain which visual cues within the sprayer and its environment will be needed by supervisors and if these cues can be replaced with indicators.

Limitations The conclusions presented in this paper may be biased by the fact that none of the users who participated in these studies had actual experience with autonomous agricultural sprayers. Their survey responses must be viewed within this context. In moving towards the design of an interface for a remotely-supervised autonomous sprayer, engineers must conduct further analysis during prototype testing to ensure that the conclusions stated in this paper apply in the context of remote supervision of an autonomous agricultural sprayer.

\section{ACKNOWLEDGEMENT}

This research was funded by the Natural Sciences and Engineering Research Council of Canada (NSERC).

\section{REFERENCES}

Alexander, R., N. Herbert, and T. Kelly. 2009. "The role of the human in an autonomous system," Proceedings of the 4th IET System Safety Conference. 1 - 6. London, UK. 26-28 October 2009. https://doi.org/10.1049/cp.2009.1536

Blackmore, B.S., H. Griepentrog, S. Fountas, and T. Gemtos. 2007. "A Specification for an Autonomous Crop Production Mechanization System". Agricultural Engineering International: the CIGR Ejournal. Manuscript PM 06 032. Vol. IX. September. Christopher D.W., D.L. John, L. Yili, E. Sallie and B. Gordon. 2004. An Introduction to Human Factors Engineering. 2nd ed. Upper Saddle River, NJ: Pearson Prentice Hall. pp. 185-193.

Deeken, H., T. Wiemann and J. Hertzberg. 2018, June. A Spatio-Semantic Model for Agricultural Environments and Machines. In International Conference on Industrial, Engineering and Other Applications of Applied Intelligent Systems (pp. 589-

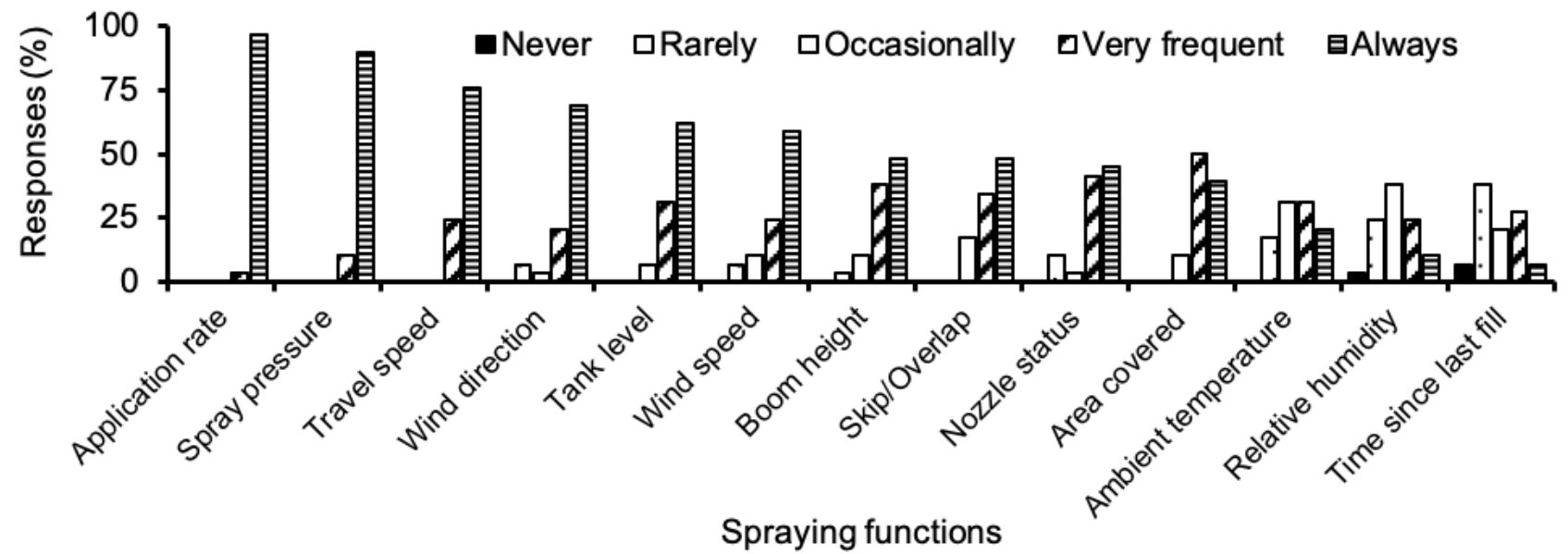

Fig. 18: Respondents' opinions regarding how frequently or rarely they view or would need each spraying functions $(\mathrm{n}=\mathbf{2 9})$. 


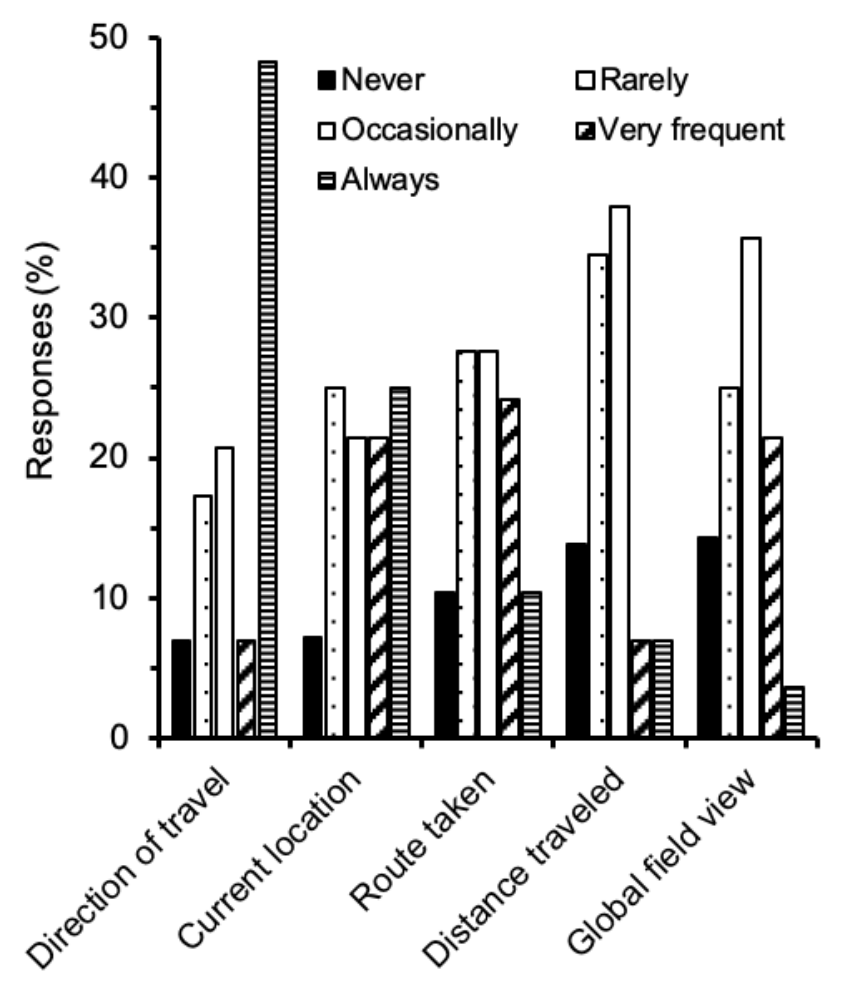

Navigation features

Fig. 19. Respondents' opinions regarding how frequent or rarely they view or would need each navigation feature $(n=29)$.

600). Springer, Cham. https://doi.org/10.1007/978-3319-92058-0 57

Dorais, G., Bonasso, R. P., Kortenkamp, D., Pell, B. and Schreckenghost, D., 1999. Adjustable autonomy for human-centered autonomous systems. In Working notes of the Sixteenth International Joint Conference on Artificial Intelligence Workshop on Adjustable Autonomy Systems (pp. 16-35).
Endsley, M. R., B. Bolte and D. G. Jones. 2003. Designing for situation awareness: an approach to user-centered design. London; NY: Taylor Francis. https://doi.org/10.1201/9780203485088

John Deere. 2018. John Deere Machine Sync: Synchronize your Machines and Logistics for True "on-the-go Harvesting".

https://www.deere.ca/en CA/docs/pdfs/farmsight/

Lewis, Michael., 2013. Human Interaction with Multiple Remote Robots. Reviews of Human Factors and Ergonomics, 9(1): 131-174. https://doi.org/10.1177/1557234X13506688

Madni, A., Y.Y Chu and A. Freedy. 1983. Intelligent interface for remote supervision and control of underwater manipulation. In OCEANS'83, Proceedings, 106-110. IEEE.

Mark, R. L. and R.B. James. 2008. Introduction to Human Factors and Ergonomics for Engineers. NY, USA. ISBN: 978-0-8058-5308-7.

Meusel, C., N. Kelly, S. Gilbert, M. Dorneich, B. Gilmore and B. Newendorp. 2015. Operator-Centered Task Analysis: A Hybrid Methodology for HumanMachine Interaction Observation in the Field. Proceedings of the Human Factors and Ergonomics Society Annual Meeting. September 2015. 59(1): 841845. https://doi.org/10.1177/1541931215591253

One-stop automation. Seed Processing controls. 2018. https://www.one-step.ca/seedplant.html. Accessed: 2018/09/24.

Rakhra, K. A., D. D. Mann and B. Behzad. 2013. UserCentered Information Display Design for Tractor Air Seeder Systems. CSBE/SCGAB 2013 Annual Conference, University of Saskatchewan, Saskatoon, Saskatchewan. July 7-10.

Rakhra, K. Aadesh, and D. D. Mann. 2014. Design guidelines review and conceptual design of a usercentered information display for mobile agricultural machines. ASABE and CSBE/SCGAB Annual International Meeting. Montreal, Quebec. July 13-16.

Table 2: Opinions of most respondents regarding how frequently or rarely they would use/need each parameters or features.

\begin{tabular}{|c|c|c|c|c|c|}
\hline \multirow{2}{*}{$\begin{array}{l}\text { Sprayer } \\
\text { functions and } \\
\text { features }\end{array}$} & \multicolumn{5}{|c|}{ Frequency of Use } \\
\hline & Always & Very Frequent & Occasionally & Rarely & Never \\
\hline $\begin{array}{l}\text { Machine } \\
\text { status }\end{array}$ & $\begin{array}{l}* \text { Engine speed, hose leakage, } \\
\text { and wireless signal (GPS) } \\
\text { status }\end{array}$ & $\begin{array}{l}* \text { Engine speed, } \\
\text { and agitator status }\end{array}$ & $\begin{array}{l}\text { Fuel level, engine } \\
\text { temperature, and engine } \\
\text { oil pressure }\end{array}$ & $\begin{array}{l}\text { Battery status, tire } \\
\text { pressure, and tire } \\
\text { slippage }\end{array}$ & \\
\hline $\begin{array}{l}\text { Spraying } \\
\text { functions }\end{array}$ & $\begin{array}{l}\text { Travel speed, wind speed, } \\
\text { wind direction, spray } \\
\text { pressure, application rate, } \\
\text { nozzle status, boom height, } \\
\text { skip/overlap, and tank level }\end{array}$ & $\begin{array}{l}\text { Ambient } \\
\text { temperature, area } \\
\text { covered, }\end{array}$ & Relative humidity & Time since last fill & \\
\hline $\begin{array}{l}\text { Navigation } \\
\text { features }\end{array}$ & $\begin{array}{l}\text { Direction of travel, and } \\
* \text { current location }\end{array}$ & & $\begin{array}{l}\text { Distance traveled, global } \\
\text { field view, and *route } \\
\text { taken }\end{array}$ & *current location & \\
\hline
\end{tabular}


Reising, J.M., 2003. Uninhabited Military Vehicles: What Is the Role of the Operators? (No. RTO-MP-088). Air force research lab Wright-Patterson AFB OH.

Schreckenghost, D., T. Fong and T. Milam. 2008. Human supervision of robotic site surveys. In: American Institute of Physics Conference Proceedings. 969 (1): 776-783). January.

Stentz. A., C. Dima, C. Wellington, H. Herman and D. Stager. 2002. A system for Semi-Autonomous Tractor Operations. Autonomous Robots. 13: 87-104. https://doi.org/10.1023/A:1015634322857

Stone, D., C. Jarrett, M. Woodroffe and S. Minocha. 2005. User Interface Design and Evaluation. Elsevier.

Vellidis, G., V. Liakos, M. Tucker, C. Perry, J. Andreis, C. Fraisse and K. Migliaccio. 2015. A smartphone app for precision irrigation scheduling in cotton. In: J.V. Stafford (Ed.), Precision Agriculture '15 Proceedings of the 10th European Conference on Precision Agriculture (10ECPA), Tel Aviv, Israel, p701-708. https://doi.org/10.3920/978-90-8686-8148 8 87

Young, S. 2003. Design of an Agricultural Driving Simulator for Ergonomics Evaluation of Guidance Display. M.Sc. thesis. Winnipeg, MB: Department of Biosystems Engineering, University of Manitoba.

Zhang, C and J. M. Kovacs. The Application of Small Unmanned Aerial Systems for Precision Agriculture: A Review. Precision Agriculture.

\section{APPENDIX}

\section{Appendix A: Phase 1 Questionnaire.}

Instruction: Please answer the questions below as honestly and accurately as possible. The questions with radio button (circle) require only one response. For questions with blank, open responses are encouraged.

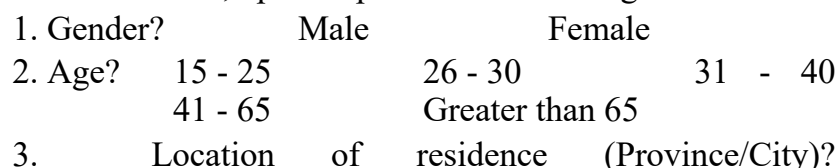

4. Are you a farm owner or custom applicator? Farmer Custom Applicator Other:

5. How many years of spraying experience do you have?

6. What type of sprayer do you use? Self-propelled Pull-type sprayer Both

7. Would you accept a fully autonomous (driverless) sprayer? Yes No

If No, what changes should be made before you would accept an autonomous sprayer? Please comment:

8. How would you expect to interact with a fully autonomous (driverless) sprayer? Please comment:

Section 2: Autonomous (Driverless) Sprayer

Overview: Remote supervision simply means monitoring the various activities and conditions of a system or machine from a distance without having direct contact with the system or machine. Hence, the purpose of this section is to get your opinion on how you feel about the concept of monitoring an autonomous (driverless) sprayer from a remote location and your expectations when interacting with such a sprayer. With this in mind;

1. How familiar are you with the general concept of "REMOTE SUPERVISION"? Very familiar Somewhat familiar Neutral Somewhat unfamiliar Very unfamiliar

2. Do you like the idea of remote supervision? Yes No

3. Have you monitored any farm activities remotely? Yes No

If Yes, how satisfied or dissatisfied were you with the outcome? Very satisfied Somewhat satisfied Neutral Somewhat dissatisfied Very dissatisfied

4. How comfortable or uncomfortable would you be supervising the operation of a fully autonomous (driverless) sprayer from a remote location? Choose one

$\begin{array}{ll}\text { Very comfortable } & \text { Somewhat comfortable } \\ \text { Neutral } & \text { Somewhat uncomfortable } \\ \text { Very uncomfortable } & \end{array}$

5. In the case of the spraying operation, where would you prefer the remote station to be located when monitoring a fully autonomous (driverless) sprayer?

Close to the field Farm office

Outside the farm Anywhere

6. What type of display would you prefer to remotely supervise a fully autonomous sprayer?

Portable Stationary

Other:

7. How would you like to initiate the fully autonomous (driverless) sprayer to commence operation?

$\begin{array}{lll}\text { Start manually } & \text { Send txt } & \text { Use remote } \\ \text { Tab/button } & \text { Other: } & \end{array}$

8. Which of these elements will you require to remotely determine if the autonomous sprayer is functioning properly?

Engine temperature Oil pressure

Hose leakage Engine speed (rpm)

Tire pressure Fuel level

Boom folding (fold/open) Spray pressure (psi) Agitator status Other:

9. Which of these elements will you require to remotely monitor the actual spraying operations?

Boom height Spray pressure (psi)

Daily (ambient) temperature

Nozzle status Application rate (gal/ac)

Altitude Time taken

Delivery rate (gal/min) Humidity

Current task Skip/double application

Wind speed Area covered (ac)

Ground/Travel speed (mph) Wind direction

Other: 
10. Which of these elements will you require to remotely monitor the movement" of an autonomous sprayer?
Route taken
Current location
Compass
Overhead field view
Distance traveled
Other:

11. Would you require live video of the spraying operation to remotely understand what the sprayer is doing?

Yes

No

If "Yes", which of the views will you require live video?

Right boom Field ahead (front view)

Left boom Rear view

Other:

12. what if it is only possible to provide live video of only "ONE VIEW", which view will you prefer?

$\begin{array}{ll}\text { Right boom } & \text { Field ahead } \\ \text { Rear view } & \text { Left boom }\end{array}$

Other:

13. In what form will you prefer to communicate with the fully autonomous sprayer?

Text Audio Button/Tab

Other:

14. Which of these conditions require warning/notification during spraying operation?

Skip/Double application

Obstacle detected

Spray tank almost empty

Route change

Plugged nozzle

Unexpected shutdown

Loss of GPS signal

Machine breakdown

Task completion

Low fuel

Other:

15. How would you rate the level of warning for each of these conditions?
1. Very critical
2. Somewhat critical
3. Critical
4. Somewhat uncritical
5. Very uncritical

\begin{tabular}{cl}
\hline Parameters & Ratings \\
\hline
\end{tabular}

Fuel level drop

Tank level drop

Detecting obstacle

Nozzle plugging

Route change

Unexpected shutdown

Task completion

Skip/double application

Machine breakdown

Loss GPS signal

Others:

16. Any other suggestions that will be required to remotely supervise the autonomous sprayer? Please comment:

\section{Appendix B: Phase 2 Questionnaire.}

Instruction: Please answer the questions below as honestly and accurately as possible. The questions with radio button (circle) require only one response. For questions with blank, open responses are encouraged.
1. Gender?
Male
Female

$\begin{array}{lll}\text { 2. Age? } & 15-25 & 26-30 \\ & 31-40 & 41-65 \\ & \text { Greater than } 65 & \end{array}$

3. Location of residence (Province/City)?

4. Are you a farm owner or custom applicator?

Farm owner Custom Applicator

Other:

5. How many years of spraying experience do you have?

6. When was the last time you operated a sprayer?

7. Use the rating scale ( $1-5)$, please indicate how frequently or rarely you need the following parameters/functions.

Rating scale:
1. Never
2. Rarely
3. Occasionally

4. Very frequent 5. Always

\begin{tabular}{|c|c|}
\hline Potential parameter & Rating \\
\hline \multicolumn{2}{|l|}{ Fuel level } \\
\hline \multicolumn{2}{|l|}{ Engine temperature } \\
\hline \multicolumn{2}{|l|}{ Engine oil pressure } \\
\hline \multicolumn{2}{|l|}{ Battery status } \\
\hline \multicolumn{2}{|l|}{ Engine speed } \\
\hline \multicolumn{2}{|l|}{ Global field view } \\
\hline \multicolumn{2}{|l|}{ Hose leakage } \\
\hline \multicolumn{2}{|l|}{ Ambient temperature } \\
\hline \multicolumn{2}{|l|}{ Relative humidity } \\
\hline \multicolumn{2}{|l|}{ Wind direction } \\
\hline \multicolumn{2}{|l|}{ Direction of travel } \\
\hline \multicolumn{2}{|l|}{ Distance traveled } \\
\hline \multicolumn{2}{|l|}{ Area covered } \\
\hline \multicolumn{2}{|l|}{ Wireless signal status } \\
\hline \multicolumn{2}{|l|}{ Current location } \\
\hline \multicolumn{2}{|l|}{ Route taken } \\
\hline \multicolumn{2}{|l|}{ Time since last fill } \\
\hline \multicolumn{2}{|l|}{ Spray pressure } \\
\hline \multicolumn{2}{|l|}{ Application rate } \\
\hline \multicolumn{2}{|l|}{ Agitator status } \\
\hline \multicolumn{2}{|l|}{ Nozzle status } \\
\hline \multicolumn{2}{|l|}{ Travel speed } \\
\hline \multicolumn{2}{|l|}{ Tire pressure } \\
\hline \multicolumn{2}{|l|}{ Tire slippage } \\
\hline \multicolumn{2}{|l|}{ Wind speed } \\
\hline \multicolumn{2}{|l|}{ Tank level } \\
\hline \multicolumn{2}{|l|}{ Skip/Overlap } \\
\hline Boom height & \\
\hline
\end{tabular}

Other (please specify and include rating): 